\title{
Using Interface Design with Low-Cost Interactive Whiteboard Technology to Enhance Learning for Children
}

\author{
Chien-Yu Lin ${ }^{1}$, Fong-Gong $\mathrm{Wu}^{2}$, Te-Hsiung Chen ${ }^{3}$, Yan-Jin $\mathrm{Wu}^{4}$, \\ Kenendy Huang ${ }^{4}$, Chia-Pei Liu ${ }^{5}$, and Shu-Ying Chou ${ }^{6}$ \\ ${ }^{1}$ Department of Special Education, National University of Tainan, \\ 33, Sec. 2, Shu-Lin St.,Tainan, Taiwan 700, R.O.C \\ linchienyuamail.nutn. edu.tw \\ ${ }^{2}$ Department of Industrial Design, National Cheng Kung University, \\ 1, Ta-Hsueh Road, Tainan, Taiwan 701, R.O.C. \\ fonggong@mail.ncku.edu.tw \\ ${ }^{3}$ National Tainan School for the Hearing Impaired, 52, Xinyi Rd., \\ Xinhua Township, Tainan County 712, Taiwan,R.O.C. \\ wolla98@gmail.com \\ ${ }^{4}$ Graduate Institute of Assistive Technology, NUTN, 33, Sec. 2, \\ Shu-Lin St., Tainan 700, Taiwan, R.O.C. \\ genius1106@hotmail.comm \\ ${ }^{5}$ Municipal Jinsyue Elementary School, 47, Nanning St, Tainan 700, Taiwan, R.O.C. \\ \{Kennedy0845, elixir416, swim-s\} @yahoo.com.tw \\ ${ }^{6}$ Tainan Municipal Heshun Elementary School, 5, Lane 178, Sec. 5, \\ Anhe Rd.Tainan, Taiwan, R.O.C.
}

\begin{abstract}
This study attempts to make use of interactive whiteboard as an interface for children with learning disabilities. Using flash software to design teaching materials with the assistance of interactive whiteboard could also be developed in the children's learning. When detected by a wiimote and infrared light device, corresponding information appears on a screen to increase the interaction aimed at children with learning disabilities by adopting an enhanced intuitive learning method. This study is divided into training and testing steps. The training step allows researchers involved in special education to acquire low-cost interactive whiteboard skills and to develop a unit course for children with learning disabilities. The participants are children with disabilities in the testing step. In this study, the application of technological innovations relies upon user-interface design, which facilitates users' control ability and interaction with an innovation, to convert the technical capabilities into a usable and friendly teaching material.
\end{abstract}

Keywords: interactive, assistive technology, teaching materials, children, wiimote.

\section{Introduction}

The study utilizes wiimote equipments of assistive technology and applications of flash software so that teachers teaching for normal or resource classes in kindergarten 
and elementary school enable to improve students' learning interest, especially for students who have difficulty following the scheduled learning progress [1].Computerbased instruction is widely used in special education. Special education teachers sometimes may have trouble teaching their students to use different computer tools[2], and advances in computer technology replacing translation of traditional paper questionnaires with novel display versions[3].Through the assistance of assistive technology and the demonstration of multimedia design, teachers have enough ability to produce the learning materials of custom-made design in order to support learning disabled students to absorb knowledge[4][5]; user-friendly design is defined as a structural design of an interface[6][7], and teaching interaction procedure is a systematic form of teaching where teachers use to describe their behavior[8].

This study is suitable for students with learning disabilities in resource class and children in kindergarten. The research takes pupils as the main body and divides into two part- the design of teaching materials and the demonstration of students' works. Teachers teaching for resource classes in elementary schools can not only participate in this study directly but also perform the outcome of the study to students right away. Because this device is easy to use, what participants have to do is to operate infrared light, a prototype which relies on the desire of patients to design. In addition, the apparatus can adjust the size and scope of projection. This kind of customized design is low-cost and less than US 40; therefore, children are also able to complete the whole study at home. The Interactive whiteboard technology consists of a large board connected to both a ceiling-mounted projector and a laptop computer that can connect to the internet via the school's wireless network. The projector displays the image from the computer screen on the board. The computer can then be controlled by touching the board with a wireless IR device that functions much like a PC mouse [9]. Interactive whiteboard systems comprise a computer linked to a data projector and a large touch-sensitive electronic board displaying the projected image. Children or teachers can manipulate objects on the screen directly by IR device[10].

Through the continuous progress on information media, functions of interface become more complicated day by day. The purpose of this research is to help children to learn with new teaching materials. Because intuition is an operating feature of assistive technology, it is unnecessary for operators to use complicated input methods, such as using a mouse or keyboard. Therefore, it is easier for children to use interface, to have realer feelings, and to experience a new interactive way. The study proceeds from case study and develops into operating interface and assistive equipments. Under practical exercises and operating processes of teachers and students from kindergartens and elementary schools, the research can observe the obvious differences between the traditional and the custom-made design of teaching material when displaying students' works. Students also very enjoy custom-made teaching materials. Therefore, according to the outcome of the study, the study is successful. Information and communication technology is a powerful tool for learning, which has prominent influences on helping teachers explain difficult concepts, giving access to a huge range of examples and resources, and inducing pupils to engage in learning easily[11].

HCI exists at the junction of computing sciences, design arts, and social sciences. Human-computer interaction is a discipline concerned with the design, evaluation and implementation of interactive computing systems for human use[12]. The goal of 
interaction design subfield within HCI is to improve the experience for students with learning disabilities of direct interaction. Computer-mediated communication facilitates the understanding of communication patterns, forms, functions and subtexts, which can in turn engender an understanding of how to derive meanings within such context[13]; patterns or figures are increasingly being used not just in education but also in many other areas such as software engineering, engineering and business management, and are also frequently advocated for teaching humancomputer interaction principles[14].

The interfacial design of assistive teaching materials makes use of interactive whiteboard. With one mouse click corresponding sound then appears, which enables to help students learn according to their own preference.In studies related to the interactive whiteboard, it is indicated that the interactive whiteboard technology has the potential of supporting teaching and learning[15].This assistive technology of interactive design describes a new design for teaching materials developed in the frame of a research project supported by information interface tools[16]. The introduction of basic education or special education-based computer aided tools in the routine development process of education is truly important.The display of multimedia teaching materials relies on the operation of a mouse; however, for students with learning disabilities, learning how to use a mouse becomes a learning burden. The study makes use of wiimote and interactive whiteboard. The application of an infrared emitter is similar to that of a stylus of a tablet computer. The design of learning interfaces adopts an intuitive design while the design of teaching materials adopts flash software to invent interesting animations in order to raise students learning motives. In addition, students not only can truly experience the vivid teaching materials but also are impressed by them.

\section{Method}

Thanks Johnny Chung Lee[17] who creates a program about low-cost multi-point interactive whiteboards using the wiimote and shares freely on his website tp://johnnylee.net/projects/wii/. Wiimote is the controller of wii. The fore part of wiimote is equipped with infrared camera which enables to receive infrared light while its interior provides Bluetooth for communication purpose; that is to say, it is available to connect with other computers possessing by Bluetooth apparatus. Therefore, the study is able to integrate the outcome of flash and to develop teaching materials for children.

\subsection{Equipment}

The theory that the study applies is making use of Bluetooth to connect a computer and a wiimote. By means of infrared emitter, wiimote can track the accurate launching location of infrared light and then generates a simple whiteboard. According to the course design of participating teachers, image projection in the study is divided into two categories.

First category: A projector shows images on the wall or the projector screen. And let the wiimote point to projection position. Based on the requirement of students, the 
range of exhibition can be adjusted. For students with deep short sight, for instance, we can make use of amplification displaying a larger size in order to improve inconvenience for short-sighted students because the presentation common computer monitors displaying is too small, as Fig. 1.left illustrated. Second category: Let wiimote point to a computer monitor which originally merely has the display function. With the assistance of wiimote, the computer monitor thus becomes a touch screen, as Fig. 1.right illustrated.

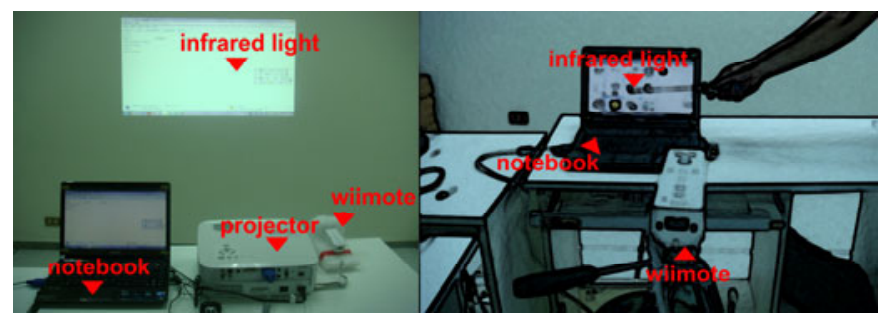

Fig. 1. Display how to use this assistive technology

The display mode of these two methods is an intuitive learning tool. The operator not needs to use a mouse as a tool, especially for children with learning disabilities who therefore do not have to learn the use-pattern of the mouse.Students will raise their interest toward learning and lessen the generation of frustration during their learning processes.

An interactive whiteboard is an interactive display interface that connects to a computer and a projector. A projector projects onto a board's surface that children can control the display by using a pen or other devices, but it cost so expensive; teachers could not use them in many place. Since the wiimote can track sources of infrared light, it can track infrared light led in the tip. In this research, teaching materials are designed by flash software and use interactive whiteboard to develop children's abilities. According to the requirement and preference of students, participating junior and elementary teachers in the study proceed to devise and adjust the design of infrared emitter.

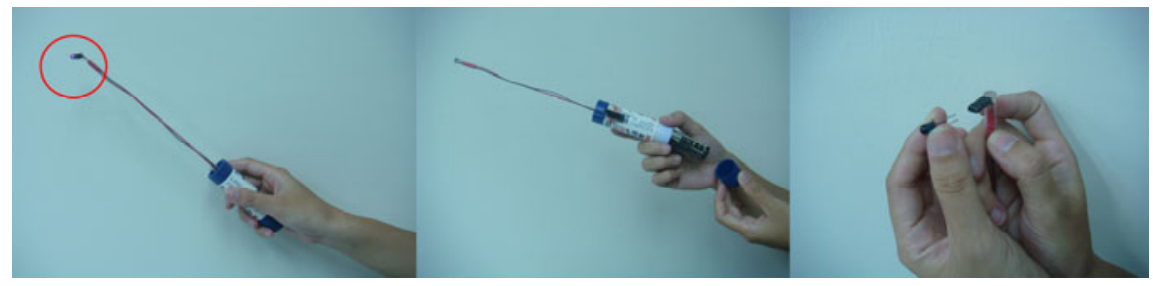

Fig. 2. Infrared emitter design 1

Fig. 2. is designed by teacher Te-Hsiung Chen. Because children with disabilities are generally incompetent at manipulating operational tools and their action 
sensibilities are also not nimble enough, teacher Chen therefore makes use of microswitch to launch infrared emitter. In addition, in the aspect of infrared emitter, in order to prevent wiimote receiver from the interruption of the location of the body resulting from the left or right hand operation of the operator, teacher Chen determines to extend launching section. This improving design creates distance between hand and launching section, and induced effect is better than before.

Fig. 3. is the design of teacher Kenendy Huang. Teacher Huang considers children are not good at holding a pen, so creating a ring style of infrared emitter; therefore, children can just wear the ring on their finger. Furthermore, teacher Huang also devises infrared emitter in a glove form. The tool is in a startup state when children's palms press on the wall, which seems like the machine responds once their hands only touch the wall. It is a certainly humanized design for children to absorb knowledge because it is unnecessary to teach them how to operate learning tools.

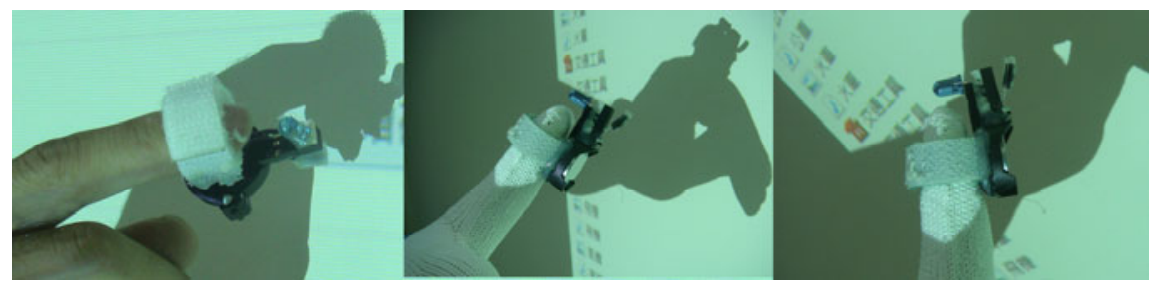

Fig. 3. Infrared emitter design 2

Figure 4 is designed by teacher Chia-Pei Liu. The shape of toy gun is the sample when teacher Liu attempts to design the shape of infrared emitter so as to evoke children's curiosity because they will desire to hold the toy gun to play. As soon as children press the power switch of the toy gun, the screen will make a difference, which not only incite their interest but also stimulate their motivation of learning.

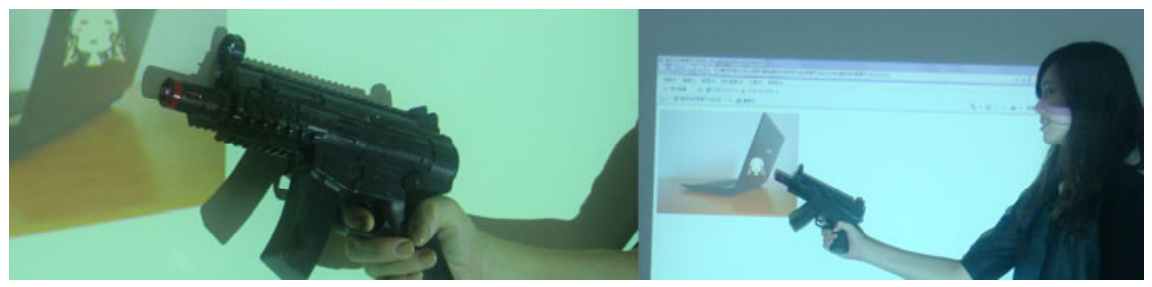

Fig. 4. Infrared emitter design 3

\subsection{Participants}

This research starts with the design of digitized teaching materials, and with the application of low-cost interactive whiteboard, therefore, this research is accomplished by carrying out two levels. The first is to select teachers from elementary and junior high schools, and teach them how to use flash software. The teachers will design interactive teaching materials, according to the need and age of 
the students they teach in their schools. Firstly, the researcher demonstrates how to use flash to design teaching materials. Then participatory teachers propose directions of their courses, and begin to design their teaching materials. The second level is that teachers set the teaching materials they designed in the schools, and let students operate digital teaching materials practically. At the same time teachers have to observe the children during their operating process, and record their feedbacks.

\section{Case Study}

Children always need repeat training and students with learning disabilities have difficulty concentrating on teaching materials; this study therefore attempts to introduce the concept of custom-made learning for teaching materials. The learning materials are customized for students themselves so as to improve their learning interest. The range of custom-made application is considerably extensive, including attire, architecture, medical care, rehabilitative instrument, etc. This study begins from assistive teaching, which provides diverse learning methods in the design of teaching materials. Using infrared emitter and interactive whiteboard can link to corresponding information, which is able to increase the attraction and intimacy of teaching materials. Here are two cases and explanations of this study.

\subsection{Case 1}

Case 1 is the teaching of Chinese characters. The teaching material of Chinese characters is divided into categories, including stationery, fruit, transportation, sport, furniture, animal and cooker, and some other Chinese phrases being used often in our daily life. Take the category of fruit for instances, teacher $\mathrm{Wu}$ puts vocabularies like "watermelon", "strawberry", "pineapple" forward as daily words.

Fig. 5.left is displayed in resource class. In the original teaching process, the general teaching method of word recognition is difficult for the student. Therefore, teacher $\mathrm{Wu}$ adopts multi-media teaching method of Chinese characters, which is different from the traditional style of learning, and uses pictures and sounds to help him memorize phrases. In this teaching and learning activity, the teacher introduces and demonstrates how to operate first, and then the student operates it on their own.

Because these students are very interested in computers, they intend to stay longer when seeing the pictures that interest them. Fig. 5.right shows teacher demonstrates how to put the appliance of infrared emitter on the word, the corresponding picture and pronounce of the word. This design of digital teaching material offers an intuitive way of learning for students when they learn new words.

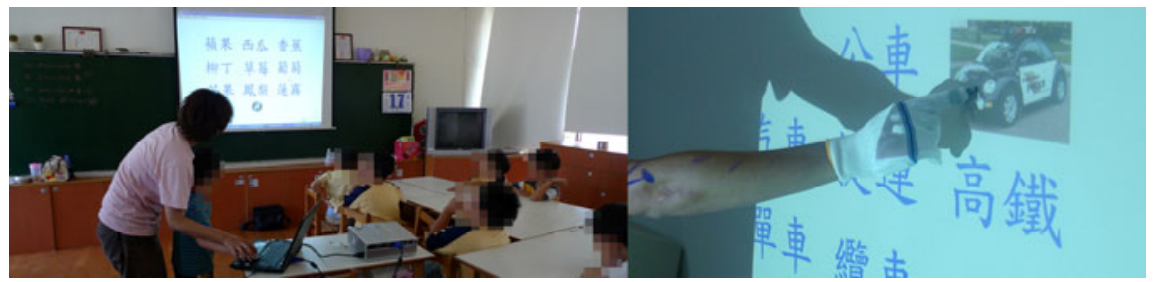

Fig. 5. Course of Chinese 


\subsection{Case 2}

Case 2 is to learn the concepts of third dimension. Students of teacher Chou, ShuYing have poor concepts of flexible, therefore, teacher Chou designs interactive effect with the application of objects that are often seen by children, and with the assistance of flash.

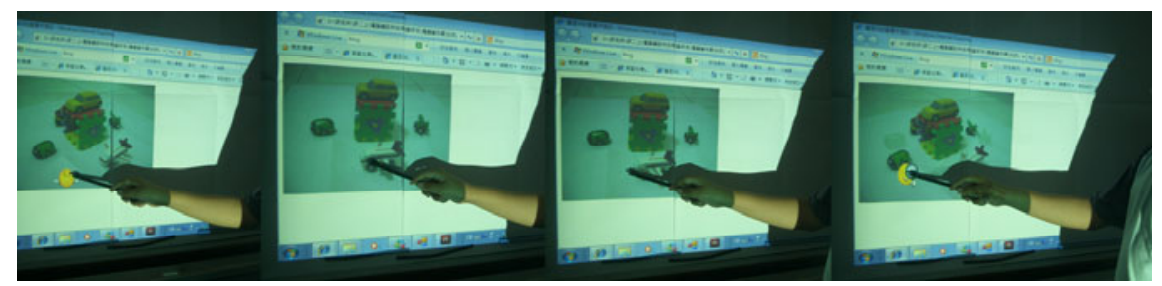

Fig. 6. The course of space training

The teacher makes use of the mighty interactive speciality of wiimote to design this lesson. The teacher is able to understand students' cognition of left and right, and concepts of extensity. Students show that it is very novel to use wiimote, as show in Fig. 6.

\section{Conclusion}

Digitized teaching material is also a trend, owning to its feature of interactive speciality that possesses immediate feedbacks. Moreover, with the support of wiimote, interactive whiteboard will be able to offer teachers and more students different opportunities to learn. For children, they can get immediate feedbacks because of the interactive speciality, which increases their motivation of learning.

Interface design can be mixed in the development of children, through the interactive speciality of information equipments, plus teachers' research and development for the design of teaching materials. Especially for special students, through the application of appliances, limits are decreased. Special thanks many teachers from elementary and junior high schools, who, for the arrangements of courses, have consideration for students' individual differences. Besides basic teaching aids, they propose many ideas and practice them in class.

As for teachers, in the design of teaching materials, this digitized learning process is certainly friendly. Therefore, it is easy to popularize digitized teaching materials to other teachers so as to accomplish teaching materials together.Interacting with computers reflects the movement within the interactive whiteboard. Some of the topics in designed teaching units make interactive interface design of assistive technology as their learning goals. Technology-based learning focuses on content learning in order to explore more user-centred and collaborative approaches in learning aspect. The importance of information and communication skills of interface design in the future has been asserted to support the development of these skills and tools in schools. Students need to possess the capability to use technology and 
information. Teachers therefore can integrate information technology into teaching activities. To efficaciously promote teaching effectiveness is the primary direction and the main goal for the school and teachers. Teaching materials as well as teaching methods have been continuously developed and innovated, especially in technological assistive tools.

Living in the era with the advance of technological assistive tools, students with special needs have a more convenient life when absorbing knowledge. By virtue of innovative ideas of serious teachers, students are able to receive a better opportunity to acquire knowledge. The student is concentrated most of the time during the operating process. Because children are very interested in computers, using multimedia to teach and learn is easier to give rise to the student's motivation of learning than general activities which use books or pencils and papers. And with pictures and sounds as hints, the scaffold of learning is built up. From the children used the interactive teaching materials, some children feel that the learning processes are no longer so difficult.

This multi-media teaching material is presented through multi-senses, which makes the content more vivid, and adds interest to the process of learning. Students can also choose learning method (visual approach, auditory approach) which is suitable for them to learn, this impression deepens more, and the effect of learning is better; moreover, it saves time. Furthermore, thanks to application information interface, students are inclined to absorb knowledge actively and aggressively. They can learn independently with no need of other's assistance. Interactive media interface for children with learning disabilities has become an important and helpful computeraided design for teaching materials. The interface arrangement also gives students assistance when they attempt to learn different units. There is a close link among assistive technology, special education and communication design research as well as studies that examine how interactive design of teaching materials can influence learning. Human-computer interaction is a valuable issue for learning disabled students in the future.

Acknowledgments. Special thanks National Tainan school for the hearing impaired, this work was partially supported by the National Science Council, Taiwan, under the Grant No.97-2410-H-024-018-,98-2410-H-024-018.

\section{References}

1. Klatt, B.A., Goyal, N., Austin, M.S., Hozack, W.J.: Custom-fit Total Knee Arthroplasty Results in Malalignment. J. Arthroplasty 23, 26-29 (2008)

2. Shimizu, H., McDonough, C.S.: Programmed Instruction to Teach Pointing with a Computer Mouse in Preschoolers with Developmental Disabilities. Research in Developmental Disabilities 27, 175-189 (2006)

3. Hung, P.H., Lin, C.Y., Lu, C.C., Chang, Y.Y.: Development and Application of Online Assessment for Experimental Debugging Performance. In: The 7th conference of the international test commission, p. 102 (2010)

4. Kawate, K., Ohneda, Y., Ohmura, T., Yajima, H., Sugimoto, K., Takakura, Y.: Computed Tomography-based Custom-made Stem for Dysplastic Hips in Japanese Patients. J. Arthroplasty 24, 65-70 (2009) 
5. Lin, C.Y., Hung, P.H., Lin, J.Y., Lun, H.C.: Augmented Reality-based Assistive Technology for Handicapped Children. Key Engineering Materials 439-440, 1253-1258 (2010)

6. Cho, V., Cheng, T.C.E., Lai, W.M.J.: The Role of Perceived User-interface Design in Continued Usage Intention of Self-paced e-learning Tools. Computers \& Education 53, 216-227 (2009)

7. Kim, Y.J.: The Effects of Task Complexity on Learner-learner Interaction. System 37, 254-268 (2009)

8. Leaf, J.B., Dotson, W.H., Oppeneheim, M.L., Sheldon, J.B., Sherman, J.A.: The Effectiveness of a Group Teaching Interaction Procedure for Teaching Social Skills to Young Children with a Pervasive Developmental Disorder. Research in Autism Spectrum Disorders 4, 186-198 (2010)

9. Lopez, O.S.: The Digital Learning Classroom: Improving English Language Learners Academic Success in Mathematics and Reading Using Interactive Whiteboard Technology. Computers \& Education 54, 901-915 (2010)

10. Warwick, P., Mercer, N., Kershner, R., Staarman, J.K.: In the Mind and in the Technology: The Vicarious Presence of the Teacher in Pupil's Learning of Science in Collaborative Group Activity at the Interactive Whiteboard. Computers \& Education 55, 350-362 (2010)

11. Waite, S.J., Wheeler, S., Bromfield, C.: Our Flexible Friend: The Implications of Individual Differences for Information Technology Teaching. Computers \& Education 48, 80-99 (2007)

12. Rosinski, P., Squire, M., Strange, B.: Human-computer Interaction, Interface Design, and Composition Pedagogy. Computers and Composition 26, 149-163 (2009)

13. Bower, M., Hedberg, J.G.: A Quantitative Multimodal Discourse Analysis of Teaching and Learning in a Web-conferencing Environment-the Efficacy of Student-centred Learning Designs. Computers \& Education 54, 462-478 (2010)

14. Kotzé, P., Renaud, K., Biljon, J.V.: Don't Do This - Pitfalls in Using Anti-patterns in Teaching Human-computer Interaction Principles. Computers \& Education 50, 979-1008 (2008)

15. Tataroglu, B., Erduran, A.: Examining Students Attitudes and Views Towards Usage an Interactive Whiteboard in Mathematics Lessons. Procedia Social and Behavioral Sciences 2, 2533-2538 (2010)

16. Lin, C.Y., Hung, P.H., Wang, L.C., Lin, C.C.: Reducing Cognitive Load Through Virtual Environments Among Hearing-impaired Students. In: PACCS 2010, pp. 183-186 (2010)

17. Lee, J.C.: Hacking the Nintendo Wii Remote. Pervasive Computing, 39-45 (2008) 